$811.111 ' 355$

https://doi.org/10.18485/bells.2021.13.5

\author{
Mateusz Pietraszek* \\ Universidad Complutense de Madrid \\ Madrid, Spain
}

\title{
GENDER AND LEVEL DIFFERENCES IN THE ATTITUDES TO ENGLISH PRONUNCIATION AT A SPANISH UNIVERSITY**
}

\begin{abstract}
A group of 111 Spanish university students (61 males and 50 females) were surveyed on their attitudes to English pronunciation using a sociodemographic and an attitudinal questionnaire. The L2 Motivational Self System was used as a point of departure in the analysis of the collected data. On average, advanced Spanish speakers of English at university level see the native standard as the model to imitate. The average student in the sample is also fairly satisfied with their accent in English, contrary to popular belief. It was revealed that the women found pronunciation to be more important than the men, and that the men were more prone to negative self-assessment. While the level did not affect the perceived importance of pronunciation, it did have an impact on communicative confidence and pronunciation self-rating.
\end{abstract}

Key words: English pronunciation, attitudes, gender differences

E-mail address: mat.pietraszek@gmail.com

** This paper was presented at the Fifth Belgrade International Meeting of English Phoneticians (BIMEP 2020), 20-21 March 2020, Faculty of Philology, University of Belgrade. 


\section{Introduction}

Attitudes have been widely investigated in the field of psychology over the past decades (Cunningham and Zelazo 2007: 97). Most psychological conceptualisations of attitudes refer to the natural tendency or need of human beings to evaluate objects (Ajzen 2001: 28; Jarvis and Petty 1996: 172). Those "psychological objects" may be different in nature as they may involve real-life items and beings, ideas, problems or actions (Marcinkowski and Reid 2019: 461). Evaluative judgments have also been found to be more engaging than non-evaluative judgments in neurological research (Crites and Cacioppo 1996: 320-1), which suggests they involve a special kind of cognitive processing. The very reason why attitudes are of interest to psychologists is their potential to predict behaviour as represented by the commonly accepted three-way attitudinal model comprising the cognitive, affective and behavioural components of attitudes (Marcinkowski and Reid 2019: 461). The present study is mainly concerned with the first two.

In the field of linguistics and second language acquisition research, attitudes can be defined as "beliefs, feelings and intentions" or "mental constructs acquired through experience, predisposing a person to certain feelings and reactions" (Dalton-Puffer, Kaltenboeck and Smit 1997: 116), although no agreement has yet been reached on the weight of the different components. It is worth noticing that in most early L2 motivation research, the term attitudes referred to the native speakers of the language being acquired and were measured as an almost exclusively social construct (cf. Larsen-Freeman and Long 1991: 176). Gardner (1985: 9) operationalises attitudes as "an evaluative reaction to some referent or attitude object, inferred on the basis of the individual's beliefs or opinions about the referent" based on how they have been measured in studies using statement evaluations on scales. Gardner's definition appears to be satisfactory for the purpose of this study where only self-reported reactions to statements (i.e. attitudes) were measured. In other words, the participants were asked to assess to what extent they agreed with statements evaluating different aspects of their pronunciation and English usage and those ratings were construed as manifestations of their attitudes.

Whereas the definition of attitudes is a relatively easy task, motivation as a research construct remains somewhat controversial. It has been an extremely prolific subfield of study over the past decades, reaching over 100 journal articles in the 1990s (Dörnyei and Skehan 2005: Section 8). 
Mateusz Pietraszek: Gender and Level Differences in the Attitudes to English...

Although motivation studies within applied linguistics were historically based on social psychology theories - and thus, unlike some other subfields, have had a firm theoretical foundation from the very beginning - no consensus has yet been reached regarding the exact meaning of the term motivation. Different models may be based on seemingly contradictory premises (Dörnyei 2000: 425) and the abundance of underlying psychological theories may confuse the readers as they invoke not only the cognitive, environmental and social dimensions of the human being, but also his/her personality and - most importantly - identity (Dörnyei 1998:18).

Based on a quick survey of online dictionaries, motivation could be defined as the driving force or the stimulus that makes people act. Following Dörnyei (2005: section 8), it is "responsible for why people decide to do something, how long they are willing to sustain the activity, and how hard they are going to pursue it". In other words, motivation studies are concerned with people's reasons for choosing a particular activity, their persistence and their effort in the achievement of the established goals. However, from the psychological perspective, the mechanisms underlying people's motivation are complex and the choice of factors determining motivation may differ from one theoretical model to another (Ibid.). If those are properly integrated, however, they can be enriching for our understanding of this multifaceted phenomenon (Dörnyei 1998: 117), which is nowadays seen more as a process rather than a static reflection of our instincts or as a definite goal.

Be that as it may, it is worth mentioning that motivation and attitudes were not clearly distinguished in the early studies (Larsen-Freeman and Long 1991: 175). What seems obvious, however, is the fact that both dimensions seem to be inextricably bound together, although the exact nature of the relationship may differ depending on the adopted model. Hermann (2000: 56) admits that motivations and attitudes research should take into consideration not only the learner's pre-established attitudes but also the changes in their attitudinal and value system throughout the learning process. And even more importantly, attitudes "may overlap with the cognitive domain and may even become conative" (2000: 56), or in other words, they may stimulate action in an individual who functions as a psychological unit due to the dialectic interaction between the cognitive and affective domains (Ibid.). This non-linear holistic hypothesis - as it is dubbed by Hermann (2000: 55) - is represented below. 


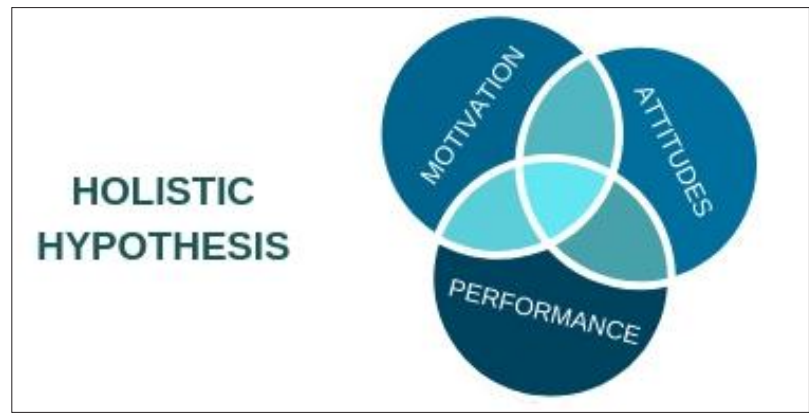

Figure 1. Holistic hypothesis

Recently, the convergence of the fields of self-theory and motivational theory in psychology has taken place (Dörnyei 2009: 10) resulting in the birth of the L2 Motivational Self System. The reason why this new field of research is relevant to this study is the fact it allows for the contemplation of the acquisition of English from a multidimensional, multicultural and multilingual perspective. Indeed, identity (or self) is of crucial concern to those investigating in the fields of World Englishes, English as a Lingua Franca or multicultural communication. Dörnyei (2009: 29) posits a threeway L2 motivational Self System which contemplates motivation from the perspective of the learner's identity:

a) Ideal L2 self - motivation is aroused when a learner speaks the L2 trying to bridge the gap between their real self and ideal self; an intrinsic aspect of motivation;

b) Ought-to L2 self - the speaker wants to meet the social requirements and avoid negative consequences; a more extrinsic aspect of motivation;

c) L2 Learning Experience - related to the immediate context learning process and its participants (group, teacher, institutions, curricula, etc.).

The fact that pronunciation is important to students seems to be evident. In a Spanish study by Edo Marzá (2014: 265), 96.1\% of the respondents felt "concerned about their own pronunciation." In another study conducted in the Spanish context by Calvo Benzies (2013: 44-5), 96\% of the sample (strongly) agreed that learning correct pronunciation was important. At the same time, there were more students who considered the acquisition of 
a native(-like) accent to be important that there were those who thought otherwise, although around $37 \%$ of those sampled had a neutral opinion on the importance of native(-like) pronunciation. Similarly, the importance of the segmental and suprasegmental features of English pronunciation was rated at an average of 7.3-8.7 out of 10 in another study with L1 Spanish and Basque speakers (Cenoz and García Lecumberri 1999: 8).

Although "successful L2 phonology learning [thus] cannot be attributed exclusively to the existence of positive attitudes towards the target accent" (Dalton-Puffer, Kaltenboeck and Smit 1997: 126), certain evidence has been found that aspects of motivation and attitudes may be correlated with the learner's phonological performance. Still, there is a dearth of available studies making a link between motivational or attitudinal variables and specific pronunciation performance - rather than just measuring the former or the latter separately. This study of attitudes is embedded within a broader research project which addresses this problem but is beyond the scope of this paper.

Taking the L2 Motivation Self System (Dyörnyei 2009) as a point of departure, the attitudinal scores (dependent variables) in this research were grouped under the following headings with relatively self-explanatory labels: pronunciation self (cf. Markus and Nurius 1986; Jenkins 2007; Moyer 2007), pronunciation importance ( $c f$. Edo Marzá 2014), communicative confidence (cf. Saito et al. 2018; Sardegna, Lee and Kusey 2018), and pronunciation self-rating (cf. Moyer 2007). The pronunciation self within this research might be defined as the evaluation of the extent to which the participants accept their pronunciation, how much they identify with their accent and/or how much they would like to modify it. Within the L2 Motivation Self System, all of those variables relate to the students' ideal selves and ought-to selves, although the distinction between the two dimensions is not always clear-cut as it is hard to tell whether a person desires something because of an externally imposed value or because it is part of their true core self.

\section{Aims and research design}

The main aim of the paper is the presentation of the results of a quantitative analysis of Spanish university students' attitudes towards the pronunciation of English from the perspective of English as an International Language or 
English as a Lingua Franca (Jenkins 2000; Walker 2010; Seidlhofer 2011). The term lingua franca is broadly understood as "any use of English for communication among speakers of different languages for whom English is the communicative medium of choice" (Seidlhofer 2011: 7) and thus should not be identified solely with Jenkins' (2000) core pronunciation features. Not only is English used all over the world but it is now also chosen as a means of communication intra-nationally with a view to internationalising degrees and facilitating the students' future careers ( $c f$. Mauranen 2012). This broad ELF perspective permeates the design of the instruments for the present research where, for example, the construct of communication confidence ( $c f$. Saito et al. 2018) is measured separately for communication with native speakers and other non-native speakers of English.

The two specific aims of the paper are (1) to gauge the participants' attitudes toward the native standard as a pronunciation model and (2) to determine the impact of the informants' gender and level of English competence on the attitudinal variables mentioned at the end of the previous section.

For the aforementioned purposes, a questionnaire consisting of 22 Likert-type items regarding attitudes to pronunciation of English as an International Language was designed and administered to the participants. The participants agreed or disagreed with the statements on a scale from 1 (strongly disagree) to 5 (strongly agree). A 30-item sociodemographic questionnaire was also devised with the aim of providing information about the participants' social and educational background. The information provided by the latter was crucial for inferential statistics as it allowed splitting the students into groups by gender and their reported level of competence in English, which were chosen as the independent variables in this study. Both questionnaires were validated by two external experts and administered to university students $(N=111)$ enrolled in bilingual and non-bilingual degrees at a university in the Region of Madrid, Spain. The vast majority of the participants were at B2 and C1 levels of competence in English, which makes it legitimate to claim this study investigated the attitudes of advanced students. Descriptive and inferential statistics were performed using IBM SPSS. 


\section{Findings}

The distribution of the language proficiency level and gender (independent variables) is presented first in this section, followed by the descriptive and inferential statistics for each dependent variable. For most attitudinal variables - with the notable exception of Pronunciation Self - the reported figures are the averaged results for all questionnaire items comprising the scale, i.e. individual item scores are not included. Those aggregate scale results were also used when conducting inferential statistics unless otherwise indicated. All inferential statistics were carried out using nonparametric tests due to the ordinal character and the abnormality of all our data as revealed by Kolmogorov-Smirnov tests. An advantage of employing the same type of tests for all analyses was the fact that effect sizes were more easily comparable. Mann-Whitney $U$ tests were used to detect gender differences, while level differences were tested using Spearman's non-parametric correlation coefficient and Kruskal-Wallis tests when considering levels B1 to C2. Additionally, as the most represented reported levels in the sample were $\mathrm{B} 2$ and $\mathrm{C} 1$, those two levels alone were compared using Mann-Whitney $U$ non-parametric tests.

\subsection{Sample description}

Amongst the 111 participants, 61 were male (55\%) and 50 were female (45\%). 82 reported their level while 29 did not. Table 1 below presents a breakdown of the participants' levels. The majority of the students had a B2 level of English while only under 10\% were below that level. There was only one participant whose level was A2, who was naturally excluded from the inferential statistics. As shown in Figure 2, the levels were evenly distributed between both genders. 


\begin{tabular}{|c|c|c|c|c|}
\hline \multicolumn{2}{|c|}{} & Frequency & Percent & Valid Percent \\
\hline \multirow{4}{*}{} & A2 & 1 & .9 & 1.2 \\
\cline { 2 - 5 } & B1 & 6 & 5.4 & 7.3 \\
\cline { 2 - 5 } & B2 & 44 & 39.6 & 53.7 \\
\cline { 2 - 5 } & C1 & 23 & 20.7 & 28.0 \\
\cline { 2 - 5 } & C2 & 8 & 7.2 & 9.8 \\
\cline { 2 - 5 } & Total & 82 & 73.9 & 100.0 \\
\hline
\end{tabular}

Table 1. Level breakdown and distribution by gender

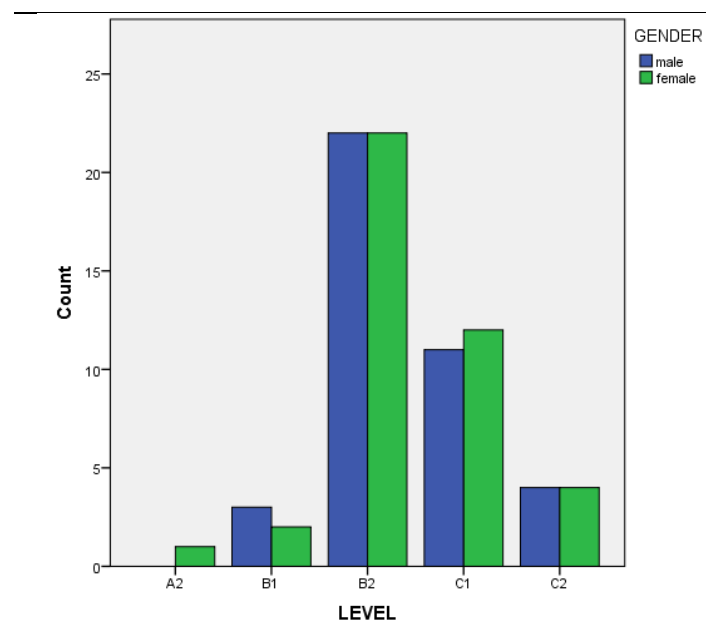

Figure 2. Level breakdown and distribution by gender

\subsection{Pronunciation Self: accent as identity}

The four questionnaire items related to the informants' Pronunciation Self were analysed separately as they were thought to measure different dimensions of the students' self-perception, i.e., (1) accent as an identity marker (My pronunciation when I speak English is part of who I am), (2) the 
desire to sound like a native speaker (I want to sound like a native speaker), (3) the satisfaction with the students' own accent (I like my accent when I speak English) and (4) the desire to lose one's foreign accent (I'd like to lose one's accent when I speak English). On average, the students strongly agreed they would like to sound like native speakers and they agreed they would like to lose their accent. At the same time, they agreed their pronunciation was part of their identity and they were not certain whether they like their accent or not ${ }^{1}$.

\begin{tabular}{|l|c|c|c|c|c|c|}
\hline & \multicolumn{2}{|c|}{ N } & Mean & Median & Mode & SD \\
\cline { 2 - 6 } & Valid & Missing & & & & \\
\hline $\begin{array}{l}\text { My pronunciation when } \\
\text { I speak English is part of } \\
\text { who I am }\end{array}$ & 110 & 1 & 3.5545 & 4 & 4 & 1.05436 \\
\hline $\begin{array}{l}\text { I want to sound like a } \\
\text { native speaker }\end{array}$ & 111 & 0 & 4.3604 & 5 & 5 & 1.00718 \\
\hline $\begin{array}{l}\text { I like my accent when I } \\
\text { speak English }\end{array}$ & 111 & 0 & 3.0541 & 3 & 3 & 1.09410 \\
\hline $\begin{array}{l}\text { I'd like to lose my accent } \\
\text { when I speak English }\end{array}$ & 110 & 1 & 3.6727 & 4 & 5 & 1.36878 \\
\hline
\end{tabular}

Table 2. Pronunciation Self variables: descriptive statistics

Mann-Whitney $U$ tests showed that gender was only a good predictor of differences in the desire to lose one's foreign accent $(U=1021.5, p=.003$, $\left.r=0.28^{2}, N=110\right)$. The effect size was small, reaching medium. The women ( $M=4.12, M d n=4, S D 1.09, n=49)$ were more willing to lose their accent than the men $(M=3.31, M d n=4, S D=1.47, n=61)$. No correlations were found between any of the Pronunciation Self variables and the four levels of competence represented in the study. However, group comparisons between B2 and C1 speakers showed a significant difference in the satisfaction with accent $(U=253, p=.001, r=0.33, N=67) . \mathrm{C} 1$

1 The average scores were interpreted using five equal intervals between the minimum and maximum possible score: 1-1.8 strongly disagree, 1.81-2.6 disagree, 2.61-3.4 undecided, 3.41-4.2 agree, 4.21-5 strongly agree

2 Size effect $r$ (expressed as a correlation 0-1) was calculated following the guidelines outlined in Herrera Soler et al. (2011). 
speakers ( $M=3.78, M d n=4, S D=.95, n=23)$ were more satisfied with their accents than B2 students $(M=2.75, M d n=3, S D 1.04, n=44)$.

\subsection{Pronunciation importance}

In order to calculate how important pronunciation was to participants, three items from the questionnaire were averaged and grouped into a pronunciation importance scale $(\alpha=.836)$. The three questions regarded the general importance of English pronunciation (English pronunciation is important for me) and its importance when communicating with native and non-native English speakers (It is important for me to have good pronunciation when I speak to native speakers/non-native speakers). The average results were fairly high regarding the mean and median, as shown in Table 3. The item I don't care how I sound in English was analysed separately as its negative correlation with Pronunciation is important for $m e$ - although expected to be high - was actually fairly low $\left(r_{s}=-0.295\right.$, $p<0.01)$.

\begin{tabular}{|l|c|c|c|c|c|c|}
\hline & \multicolumn{2}{|c|}{ N } & \multirow{2}{*}{ Mean } & Median & Mode & SD \\
\cline { 2 - 7 } & Valid & Missing & & & & \\
\hline IMPORTANCE (Scale) & 111 & 0 & 4.3784 & 4.6667 & 5 & .72820 \\
\hline $\begin{array}{l}\text { I don't care how I } \\
\text { sound in English }\end{array}$ & 111 & 0 & 1.5946 & 1 & 1 & .84615 \\
\hline
\end{tabular}

Table 3. Pronunciation Importance: descriptive statistics

While the level variable was statistically insignificant in this case, gender significantly predicted the outcomes $(U=1052.5, \mathrm{p}=.004, r=.027, N$ $=111)$, although the effect size was small. The women $(M=4.63, M d n$ $=4.67, S D=0.51, n=50$ ) were more likely to assert pronunciation was important than the men $(M=4.18, M d n=4.33, S D=0.82, n=$ 61). Students at different levels did not differ in their assessment of pronunciation importance as shown by the Kruskal-Wallis test $(p=.382)$.

Similarly, it was noted that the results for the item omitted from the scale (I don't care how I sound in English) differed between the two genders as well $(U=993.5, p<.001, r=.34, N=111)$. The men $(M=1.87$, $M d n=2, S D=.99, n=61$ ) were more likely to agree more with this 
statement than the women $(M=1.27, M d n=1, S D=0.45, n=50)$. Both the statistical significance and the effect size were higher in the case of this item in particular than for the entire scale.

\subsection{Communicative confidence and positive pronunciation self-rating}

Initially, self-rating (positive) and communicative confidence were conceived of as two different scales, each measured by two questionnaire items. The reason those two scales were grouped together for the final analyses in this study was the data-driven observation that they actually measured the same dimension, as revealed by the calculation of Cronbach's alpha $(\alpha=.858)$. Therefore, for the final inferential statistics all items were averaged and grouped under one scale comprising pronunciation confidence (I feel comfortable when speaking to native speakers/non-native speakers of English) and self-assessment (My pronunciation in English is good/People understand my pronunciation well when I speak English).

\begin{tabular}{|l|c|c|c|c|c|c|}
\hline & \multicolumn{2}{|c|}{$\boldsymbol{N}$} & Mean & \multirow{2}{*}{ Median } & Mode & SD \\
\cline { 2 - 4 } & Valid & Missing & & & \\
\hline $\begin{array}{l}\text { CONFIDENCE-POSITIVE } \\
\text { ASSESSMENT Scale }\end{array}$ & 111 & 0 & 3.5428 & 3.5 & 3.25 & .87767 \\
\hline
\end{tabular}

Table 4. Confidence-self-rating (scale): descriptive statistics

Gender had no significant effects on confidence or positive self-assessment as shown by a Mann-Whitney $U$ test $(p=.156)$. Nevertheless, the level variable was a significant predictor (Figure 3). The Mann-Whitney U test comparing B2 and C1 speakers $(U=183, p<.001, r=-.41, N=67)$ showed that $\mathrm{C} 1$ speakers $(M=4.17, M d n=4.25, S D=.62, n=23)$ rated themselves significantly higher than B2 speakers $(M=3.3, M d n$ $=3.25, S D=0.71, n=44)$. The effect size was medium. Similarly, the non-parametric Spearman's correlation test between levels (B1-C2) and the confidence-positive-assessment scale rendered statistically significant results $\left(r_{s}=.576, p<.001\right)$. 


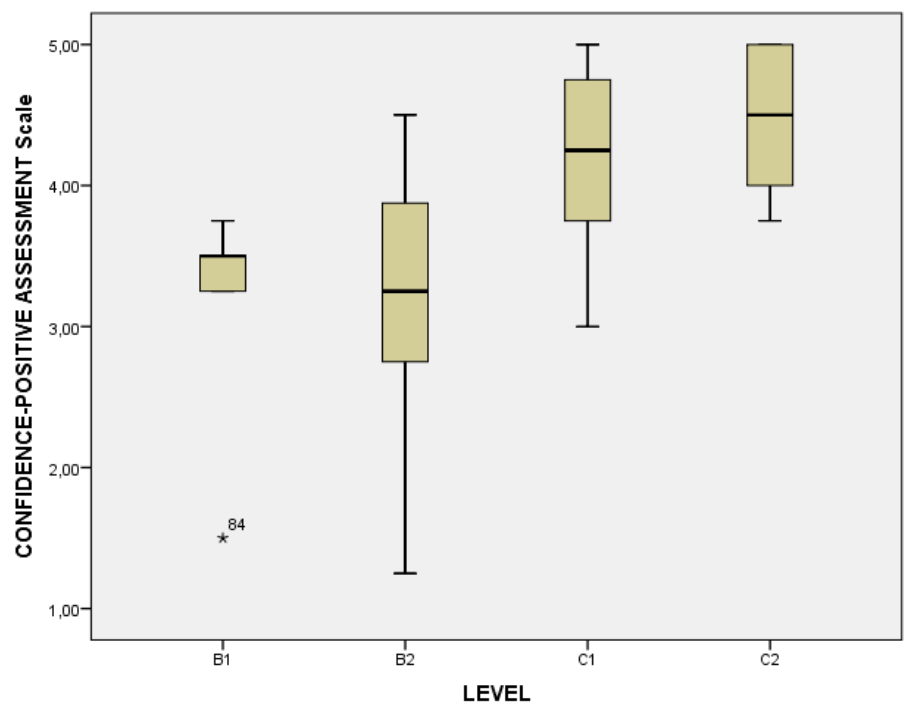

Figure 3. Level and confidence-positive assessment box plot

\section{Discussion}

The image of a Spanish university student's attitudes to pronunciation which emerges from the conducted surveys reveals that, in spite of negative popular beliefs (Galván 2010; Poyatos Soguero 2016; El Confidencial 2014; La Razón 2019), an advanced student rates their pronunciation positively. On average, they also feel confident when communicating in English both with native and non-native speakers. The descriptive statistics in this study also showed that although the students neither liked nor disliked their accent in English, the native speaker was still the pronunciation model they generally aspired to emulate. This is consistent with previous research, which reports that in this ever-changing world where non-native speakers greatly outnumber native speakers, native pronunciation is still looked up to as a model to be imitated and the belief that non-natives should conform to native standards is still alive and well (Calvo Benzies 2013; Jenkins 2007, 2014). The adherence to a native model leads to a conflict between the students' perceived real selves and their ideal or ought-to selves. While they consider their accent to be part of their identity, they would also like 
to lose it, although the participants' opinion on the latter was divided, as shown by the standard deviation of the scores, which was higher than in the case of the other items. At the same time, the self-assessment of their own pronunciation performance is relatively positive, which suggests they are satisfied with how their pronunciation serves communicative purposes, although they may not like the way it sounds. What is more, the average score showing the desire to sound like a native speaker (ideal self or oughtto self) is approximately 1.5 out of 5 higher than that showing a positive attitude towards their own accent, which suggests that the aforementioned conflict is substantial. Whether or not it could be turned into action by students, and how, is beyond the scope of this research. However, the learners' satisfaction with their own pronunciation - which goes against popular beliefs - should be emphasised and used to boost the morale of students at lower levels of proficiency, as well as to debunk the somewhat negative domestic opinion on the English spoken by Spaniards.

The effect sizes in the case of both gender and level differences were small to medium. Thus, although the scores were not dramatically divergent, c ertain significant tendencies were definitely detected. The gender difference analysis revealed that this variable was a significant predictor of the importance attached to pronunciation as well as other dependent variables, including the desire to lose one's accent and the indifference to pronunciation. As in previous studies (Calvo Benzies 2013; Cenoz and García Lecumberri 1999), pronunciation was seen as an important aspect of language acquisition across both genders. However, the women did not only consider pronunciation more important than the men did, but they were also more likely to be willing to lose their accent suggesting a stronger desire to conform to a standard, although both genders would like to sound like native speakers. Moreover, the men were more likely to state they did not care about their pronunciation in English. This suggests the male participants were more inclined to project an image of indifference when asked directly about a potential change or their emotions. These findings confirm earlier studies where girls were usually found to be more interested in language learning and boys more likely to be self-deprecating in the assessment of their language skills and motivation (cf. López Rúa 2006).

As mentioned before, this paper investigated mostly advanced students, the vast majority being between levels B2-C1, of those who reported their level. All levels considered pronunciation to be equally important. 
Although due to the numbers in the sample, we cannot be sure whether any real differences exist between $\mathrm{B} 1$ and $\mathrm{B} 2$ and $\mathrm{C} 1$ and $\mathrm{C} 2$, the post-hoc tests in this study show clearly that that $\mathrm{C} 1$ students are happier with their accent than those at the B2 level and also rate themselves better. This could be tentatively explained by the growing level of competence, which leads to a better perception of one's own performance. What is interesting is that differences were observed only between levels B2 and C1, which might suggest that only reaching $\mathrm{C} 1$ do speakers feel comfortable with their pronunciation and communication skills.

One of the obvious limitations of this study is the number of participants and the fact that data regarding the proficiency level was not available for all of them. Additionally, grouping variables into scales is necessarily an arbitrary task, albeit supported by statistical results. In this study, it might be argued, for example, that the item I like my pronunciation when I speak English refers more to the student's perceived pronunciation performance (i.e. self-rating) rather than being a variable related to the speaker's pronunciation self. Needless to say, further studies should be conducted in order to corroborate the conclusions herein and examine whether these can be extrapolated to all advanced English speakers in Spain. Yet another, perhaps the most compelling, research avenue would be contrasting attitudinal and performance scores in order to investigate the association between the two and gain insight into the relationship between reported attitudes and actual measurable skills.

\section{References}

Ajzen, I. (2001). Nature and Operation of Attitudes. Annual Review of Psychology 52 (1), 27-58.

Calvo Benzies, Y. J. (2013). Spanish EFL University Students' Views on the Teaching of Pronunciation: A Survey-Based Study. University of Reading Language Studies Working Papers 5, 41-49.

Cenoz, J. and M.L. García Lecumberri (1999). The Acquisition of English Pronunciation: Learners' Views. International Journal of Applied Linguistics 9 (1), 3-15.

Crites, S. L. and J. T. Cacioppo (1996). Electrocortical Differentiation of Evaluative and Nonevaluative Categorizations. Psychological Science 7 (5), 318-321. 
Cunningham, W. A. and P. D. Zelazo (2007). Attitudes and Evaluations: A Social Cognitive Neuroscience Perspective. Trends in Cognitive Sciences 11 (3), 97-104.

Dalton-Puffer, C., G. Kaltenboeck and U. Smit (1997). Learner Attitudes and L2 Pronunciation in Austria. WorldEnglishes 16 (1), 115-128.

Dörnyei, Z. and P. Skehan (2005). Individual Differences in Second Language Learning. Hoboken, New Jersey: Blackwell Publishing.

Dörnyei, Z. (1998). Motivation in Second and Foreign Language Learning. Language Teaching 31 (3), 117-135.

Dörnyei, Z. (2000). Motivation. In: M. Byram (ed.), Routledge Encyclopedia of Language Teaching and Learning, London/New York: Routledge, 425-432.

Dörnyei, Z. (2009). The L2 Motivational Self System. In: E. Ushioda and Z. Dörnyei (eds.), Motivation, Language Identity and the L2 Self, Bristol: Multilingual Matters, 9-42.

Edo Marzá, N. (2014). Pronunciation and Comprehension of Oral English in the English as a Foreign Language Class: Key Aspects, Students' Perceptions and Proposals. Journal of Language Teaching and Research 5 (2), 262-273.

El Confidencial (2014). Nuestro acento en inglés nos delata: estos son los errores más comunes. El Confidencial, 24/01. (30 October 2020) <www. elconfidencial.com/alma-corazon-vida/2014-01-24/nuestro-acentoen-ingles-nos-delata-estos-son-los-errores-mas-comunes_79791/>.

Galván, F. (2010). Por qué a los españoles se nos da mal el inglés. El País, 19/07. (30 October 2020) <elpais.com/diario/2010/07/19/ opinion/1279490411_850215.html>.

Gardner, R. C. (1985). Social Psychology and Second Language Learning. the Role of Attitudes and Motivation. Vol. 4. London: Arnold.

Hermann, G. (2000). Attitudes and Language Learning. In: M. Byram (ed.), Routledge Encyclopedia of Language Teaching and Learning, London/New York: Routledge, 53-58.

Herrera Soler, H., R. Martínez Arias and M. Amengual Pizarro (2011). Estadística Aplicada a La Investigación Lingüística. Madrid: EOS UNIVERSITARIA.

Jarvis, W. B. G. and R. E. Petty (1996). The Need to Evaluate. Journal of Personality and Social Psychology 70 (1), 172-194.

Jenkins, J. (2000). The Phonology of English as an International Language. Oxford: Oxford Univeristy Press. 
Jenkins, J. (2007). English as a Lingua Franca: Attitude and Identity. Oxford: Oxford Univerisity Press.

Jenkins, J. (2014). English as a Lingua Franca in the International University. London/New York: Routledge.

La Razón (2019). Los españoles son los europeos que peor hablan inglés. La Razón, 13/07. (30 October 2020) <www.larazon.es/familia/losespanoles-son-los-europeos-que-peor-hablan-ingles-PO24191608/>.

Larsen-Freeman, D. and M. H. Long (1991). An Introduction to Second Language Acquisition Research. Harlow: Longman.

López Rúa, P. (2006). "The Sex Variable in Foreign Language Learning: An Integrative Approach". Porta Linguarum: Revista Internacional De Didáctica De Las Lenguas Extranjeras (6), 99-114.

Marcinkowski, T. and A. Reid (2019). "Reviews of Research on the AttitudeBehavior Relationship and their Implications for Future Environmental Education Research". Environmental Education Research 25 (4), 459-471. Markus, H. and P. Nurius (1986). "Possible Selves". American Psychologist 41 (9). 954-969.

Mauranen, A. (2012). Exploring ELF. Academic English Shaped by Non-Native Speakers. The Cambridge Applied Linguistics Series. Cambridge: Cambridge University Press.

Moyer, A. (2007). "Do Language Attitudes Determine Accent? A Study of Bilinguals in the USA". Journal of Multilingual and Multicultural Development 28 (6), 502-518.

Poyatos Soguero, D. (2016). “¿Por qué los españoles hablamos mal inglés?” The Huffington Post, 25/05. (30 October 2020) <www.huffingtonpost. es/daniel-poyatos-soguero/por-que-los-espanoles-hab_b_10061988. $\operatorname{html} \angle>$.

Saito, K., J.-M. Dewaele, M. Abe and Y. In'nami (2018). "Motivation, Emotion, Learning Experience, and Second Language Comprehensibility Development in Classroom Settings: A Cross-Sectional and Longitudinal Study". Language Learning 68 (3), 709-743.

Seidlhofer, B. (2011). Understanding English as a Lingua Franca. Oxford: Oxford University Press.

Walker, R.. 2010. Teaching the Pronunciation of English as a Lingua Franca. Oxford Handbooks for Language Teachers. Oxford: Oxford University Press.

Received: 29 July 2021

Accepted for publication: 31 August 2021 